\title{
Arqueologia, História e Direitos Humanos: um estudo da Guerrilha do Araguaia
}

\author{
Michel Justamand \\ PatríciaSposito Mechi
}

Resumen: El artículo presenta algunas consideraciones sobre las posibles contribuciones que la arqueología puede ofrecer al conocimiento de uno de los episodios más oscuros de la dictadura cívico-militar de Brasil (1964-1985): la guerrilla del Araguaia. Ocurrió en la región norte, en la triple frontera entre los estados de Pará, Maranhão y Tocantins (la estación norte de Goiás) y organizado por el Partido Comunista de Brasil (PC do B) la guerrilla era la forma principal de lucha contra la dictadura de lo vislumbrada por esta alianza política, el contexto represivo establecido desde el golpe de Estado que se inició el último período de la dictadura brasileña. En la guerrilla, casi todos los guerrilleros murieron, muchos de los cuales están incluidos en los listados organizados por las entidades que reúnen las familias de los muertos y desaparecidos políticos de aquellos años, y los informes de asesinatos, torturas y desapariciones de campesinos de la región.

Palabras clave: arqueología, historia y derechos humanos

Abstract: This paper presents some thoughts on possible contributions archeology can offer to the knowledge of one of Brazil's civil-military dictatorship darkest episodes: Araguaia's guerrilla(1964-1985). This was held in the northern region of Brazil within the triple border of the states of Pará, Maranhão and Tocantins (at that time the northern part of the so called state of Goiás) and carried out by the Communist Party of Brazil (PC do B). The guerrilla was the main form of fight against dictatorship envisioned by that political association within a repressive context established by the military coup whotriggered the last Brazilian dictatorship period. In the guerrilla, almost all insurgents were killed, many of which are mentioned in the listings organized by entities which gather families who either had a kin killed or made disappeared in those years in a context of many reports of murders, tortures and disappearances of peasants in the region.

Keywords: archeology, history and human rights

Resumo: O artigo apresenta algumas considerações sobre algumas das contribuições que a arqueologia pode oferecer ao conhecimento de um dos episódios mais sombrios da ditadura

${ }^{1}$ Docente da UFAM - Universidade Federal do Amazonas, lotado em Benjamin Constant. Endereço: Rua General Julio Marcondes Salgado, 65, apto 52, Campos Eliseus, São Paulo, Capital, Cep: 01201-020.

Tel: 011386272 51. micheljustamand@yahoo.com.br.

${ }^{2}$ Docente da UNILA - Universidade Federal da Integração Latino Americana, em Foz do Iguaçu.

Endereço: Rua Iapó, 878, conjunto Libra, Foz do Iguaçu, Cep: 85857-650. Tel: 045 patrícia@uft.edu.br.

(C) Rev. Arqueologia Pública

\begin{tabular}{l|l|} 
Campinas, SP & v.9
\end{tabular}

No.(11)

p.122-133

suplemento

ISSN 2237-8294 
civil-militar brasileira (1964 à 1985): a guerrilha do Araguaia. Ocorrida na região norte do país na tríplice fronteira entre os estados do Pará, Maranhão e Tocantins (à época norte de Goiás) e organizada pelo Partido Comunista do Brasil (PC do B) a guerrilha foi a principal forma de luta contra a ditadura vislumbrada por essa agremiação política, no contexto repressivo estabelecido a partir do golpe de estado que deu início ao último período ditatorial brasileiro. $\mathrm{Na}$ guerrilha, quase todos os guerrilheiros foram assassinados, muitos dos quais constam nas listagens organizadas por entidades que reúnem os familiares de mortos e desaparecidos políticos daqueles anos, além de relatos de assassinatos, torturas e desaparecimentos de camponeses da região.

Palavras chave: arqueologia, história e direitos humanos. 


\section{Introdução}

O conhecimento de um dos episódios mais sombrios da ditadura civil-militar brasileira (1964 a 1985), a guerrilha do Araguaia, é um grande desafio a uma gama de pesquisadores de diversas áreas do saber. Trata-se de um episódio em que as forças repressivas que nele atuaram esforçaram-se (e ainda se esforçam) para ocultar ou mesmo negar sua existência. Ocorrida na região norte do país, na tríplice fronteira entre os estados do Pará, Maranhão e Tocantins (à época norte de Goiás) e organizada pelo Partido Comunista do Brasil (PC do B), a guerrilha foi a principal forma de luta contra a ditadura vislumbrada por essa agremiação política, no contexto repressivo estabelecido a partir do golpe de estado que deu início ao último período ditatorial brasileiro.

Uma das dificuldades para seu conhecimento foi o assassinato de quase a totalidade dos guerrilheiros que nela atuaram. Desses guerrilheiros, muitos constam nas listagens organizadas por entidades que reúnem os familiares de mortos e desaparecidos políticos daqueles anos(COMISSÃO DE FAMILIARES DE MORTOS E DESAPARECIDOS POLÍTICOS; INSTITUTO DE ESTUDOS DA VIOLÊNCIA DO ESTADO; GRUPO TORTURA NUNCA MAIS. 1996.), além de relatos de assassinatos, torturas e desaparecimentos de camponeses da região.

Outra dificuldade refere-se à negação, pelos militares, de sua existência em fins da década de 1970. Quando finalmente admitiram a existência da guerrilha, eles afirmavam que os documentos sobre ela haviam sido destruídos, o que pesquisas recentes mostram não ser verdade(MORAIS, Taís e SILVA, Eumano 2005).

Merece menção também a intimidação contínua e sistemática daqueles que vivenciaram o cotidiano da repressão: os moradores da região, em particular aqueles que foram guias do Exército durante a guerrilha e que teriam indicações dos locais onde foram mortos ou enterrados os guerrilheiros. Mesmo que muitos deles sintam-se respaldados pelas diversas ações, inclusive as da Comissão de Anistia do Ministério da Justiça, há ainda um número expressivo de pessoas que se negam a comentar o episódio, com medo das represálias que possam sofrer.

v.9
No.(11) p.122-133 suplemento 
A guerrilha foi reprimida pelas Forças Armadas, com clara preponderância do Exército, e contou com a colaboração das forças policiais locais dos estados de Goiás e Pará, além de camponeses, estes últimos forçados a colaborar sob pena de prisão, tortura e morte.

Os mais recentes estudos têm se debruçado sobre este grupo social, os camponeses, habitantes tradicionais da região, entendendo que ele teve papel fundamental no desenrolar da guerrilha e de sua repressão(MECHI, Patrícia Sposito. 2012). Discute-se que tanto para os guerrilheiros, quanto para os militares, o contato e a colaboração da população local foi decisiva, e é a partir dos relatos dos camponeses que está sendo recuperado muito da experiência social dos guerrilheiros, como também das formas repressivas que foram utilizadas pelas Forças Armadas na região.

Outro aspecto sempre presente na militância dos familiares dos mortos e desaparecidos e que vem ganhando maior problematização na produção acadêmica, refere-se a temática dos Direitos Humanos. Há diversos elementos que permitem aos pesquisadores recuperar a sua sistemática e contínua violação no Araguaia.

Nos primeiros meses após a descoberta de militantes na região - as Forças Armadas não sabiam ainda que se tratava de uma guerrilha organizada pelo PC do B - foram enviadas para a região tropas comuns, mobilizadas nas proximidades; tratava-se principalmente de policiais militares e recrutas do Exército. Ao abordarem a população para procurar descobrir elementos para enfrentar o inimigo ainda desconhecido, utilizaram largamente prisões arbitrárias e usaram-se também interrogatórios.

Esta forma de relacionamento das forças repressivas com a população, entretanto, não foi exclusividade do Araguaia e pode ser percebida em outros movimentos de luta no campo, como os movimentos dos camponeses das Ligas Camponesas, de Porecatu e da Revolta camponesa de Trombas e Formoso. Neste último, a repressão aos camponeses também se desenvolvia de forma semelhante à que relatam os camponeses do Araguaia. "A prisão, um caixote de madeira que cheirava a sangue, os espancamentos e a queima de roças e de casas, além da presença do jagunço aterrorizando os camponeses foram constantes nos conflitos em torno da posse de terra"(ABREU, S. de B. 2002). $\mathrm{Na}$ repressão à guerrilha, essas práticas, identificadas também em outros movimentos camponeses, tornaram-se cotidianas. Entretanto, no Araguaia, uma especificidade da atuação das forças repressivas junto aos camponeses era que "o ataque era indiscriminado, atingindo um número muito grande de camponeses, diferentemente de outros movimentos, nos quais se 
contavam ataques às roças e casas, às dezenas, já no Araguaia, eram centenas"(MECHI, Patrícia Sposito 2012:107).

A forma mais utilizada de repressão e intimidação dos camponeses foi a queima das roças e das casas, que tinham como uma de suas finalidades, desencorajar os moradores a prestarem auxílio à guerrilha, buscando "matá-la de fome". Ter ajudado os guerrilheiros com os produtos produzidos para sua subsistência muitas vezes significou ao camponês ser levado às prisões e às torturas(NASCIMENTO, Durbens Martins 2000:140).

Como se vê, durante a guerrilha, existiram diversas formas de reprimir o movimento que afetaram os moradores. Uma das mais mencionadas nos relatos dos camponeses foi a prisão em massa. Cerca de 300 moradores da área da guerrilha foram presos e levados para a sede do Departamento Nacional de Infraestrutura e Transporte (DNIT), também conhecida como "Casa Azul". Nela funcionava uma base militar, que se localizava na região de Bacaba. Lá, além das prisões, diversos moradores sofreram com as torturas contra eles empregadas, além de relatarem terem visto guerrilheiros presos, os mesmos que hoje estão desaparecidos, como é o caso da guerrilheira Rosinha, Maria Célia Corrêa(MECHI, Patrícia Sposito 2012:120).

Os apontamentos anteriores, sem a pretensão de explorar exaustivamente os métodos repressivos utilizados pelas Forças Armadas durante a guerrilha, servem de ponto de partida para a reflexão sobre a necessidade de estudos interdisciplinares, entre áreas do saber como a história e a arqueologia.

Nos relatos e situações repressivas mencionadas, demonstraram-se as possibilidades de haver investigações arqueológicas que poderiam iluminar pontos que a historiografia não é capaz de elucidar. O cruzamento da documentação escrita com os depoimentos são objetos de futuras prospecções (FUNARI, Pedro Paulo de Abreu 2010:56). Tal metodologia arqueológica serviria para o desenvolvimento de novos conhecimentos sobre a história da região e, consequentemente, da guerrilha.

Outro aspecto relevante que pode enriquecer o estudo da guerrilha é a inviabilidade da utilização de tropas regulares para reprimi-la. Para levar a cabo a missão de exterminar a guerrilha, foram necessárias três investidas oficiais. Entretanto, apenas quando os militares utilizaram táticas de guerrilhas e da conhecida "guerra suja" foi que se saíram vitoriosos. Este aspecto deixa claro que, no contexto do Araguaia, de selva densa, população rarefeita e com guerrilheiros adaptados à região, a derrota dos exércitos em suas formações convencionais eram iminentes. A destruição da guerrilha adveio apenas quando do abandono dos métodos 
tradicionais, utilizando-se técnicas de guerrilhas que tinham origens primitivas, que já ocorreram em campanhas de exércitos conhecidos pelo mundo(KEELEY, Lawrence $\mathrm{H}$. 2011:181).

O combate primitivo, ou a tática de guerrilha, são superiores à variedade dos chamados civilizados. Este último é um combate estilizado, ritualizado e relativamente menos perigoso. Nas táticas de combate primitivo, os inimigos são todos mortos, na maioria das ocasiões, especialmente os homens adultos, estratégia para garantir o mínimo de risco(KEELEY, Lawrence H. 2011:181). Isto é algo que guarda alguma semelhança com o que fora feito pelos militares no Araguaia, quando se buscou prender e torturar chefes de família. Outro aspecto de guerra primitiva ou de guerrilha era negar-lhes os meios de subsistência, destruindo suas produções, seja por vandalismo ou por roubo, também foram procedimentos desenvolvidos pelos militares na região.

Sequestros de mulheres e crianças também podem ter ocorrido, segundo apontam os depoimentos descritos por Mechi (MECHI, Patrícia Sposito 2012), que além de promover o terror na região (KEELEY, Lawrence H. 2011:338), levaram os camponeses a abandonar suas terras.

Acrescente-se ainda que os militares, quando de sua atuação na região do Araguaia e durante a guerrilha, utilizaram uma tortura pouco conhecida no Brasil, mas que pode guardar similaridade com outros episódios de repressão no campo como o "Buraco do Vietnã", cujo nome remete à famosa guerra travada entre os Estados Unidos e o Vietnã do Sul, entre os anos de 1955 e 1975. O "Buraco do Vietnã", portanto, teve vigência na região do Araguaia no mesmo período em que se desenvolvia a guerra no sudoeste asiático, marcada pela derrota da grande potência americana e pela utilização de táticas de guerra não convencionais pelos combatentes vietnamitas, conhecidos como os vietcongs.

\section{Arqueologia, Direitos Humanos e a Guerrilha do Araguaia}

A Arqueologia tem se mostrado uma grande aliada dos direitos humanos na América Latina, em particular ao oferecer seu aporte teórico e metodológico para desvendar os mecanismos de repressão e resistência que vigoraram nos regimes ditatoriais durante as décadas entre 1960 e 1980(JUSTAMAND, Michel; MECHI, Patrícia Sposito \& FUNARI, Pedro Paulo A. 2014). É 
assim que vemos a importância da ciência arqueológica ligada às questões da Guerrilha do Araguaia.

Tal ciência traz, atualmente, novas dimensões para os estudos sobre as ditaduras militares no continente, contribuindo na elucidação de aspectos que a documentação escrita ou oral nem sempre esclarecem, especialmente em casos em que a documentação ainda é muito fragmentária.

Nesses casos, os saberes arqueológicos estabelecem uma interface importante com a História, evidenciando outros prismas de análise em que se privilegiam os vestígios materiais, contribuindo para esclarecer os procedimentos repressivos dos regimes ditatoriais.

Contudo, é possível notar-se, por exemplo, através de exames das ossadas encontradas, que sua contribuição vai além da identificação dos desaparecidos. São importantes também os vestígios deixados nos locais onde se praticaram torturas e/ou assassinatos (como é, por exemplo, os casos do "Buraco do Vietnã"), além de possíveis análises técnicas dos instrumentos abandonados em porões dos centros clandestinos de detenção(ZARANKIN, Andrés e NIRO, Claudio 2008), inscrições e marcas deixadas em paredes(S. NAVARRETE, Rodrigo e Y. LÓPEZ, Ana Maria 2008), roupas usadas, mobiliários, entre outros. Assim, a ciência arqueológica ajuda não só na recuperação da História e da memória dos desaparecidos e na compreensão dos sistemas repressivos, especialmente sobre a documentação fragmentária deixada pelas ditaduras, na questão da Guerrilha do Araguaia, como também em muitos outros aspectos. Esperam-se das investigações arqueológicas, contribuições esclarecedoras dos procedimentos repressivos e a recuperação da História dos desaparecidos(CARVALHO, Aline Vieira de e FUNARI, Pedro Paulo A. 2009).

Algumas pesquisas já foram levadas a cabo por equipes de arqueólogos forenses na região da Guerrilha. No histórico dos moradores da região está "inscrita" a obrigação de trabalhar para os militares durante a ditadura. Recentemente as pesquisas das equipes que atuaram na região levantaram que 21 guerrilheiros teriam sido presos pelas Forças Armadas e, dentre eles, 18 foram vistos circulando pelas bases militares. Todos estão desaparecidos e não há registros oficiais sobre essas mortes(MINISTÉRIO PÚBLICO FEDERAL, Procuradorias da República do Pará, São Paulo e Distrito Federal 2002).

Essas pesquisas conseguiram seguir em frente, graças à pressão exercida fortemente pelos familiares, o que levou, em 1995, à aprovação da Lei no 9140, de dezembro de 1995(MINISTÉRIO PÚBLICO FEDERAL, Procuradorias da República do Pará, São Paulo e Distrito 
Federal 2002), dando subsídios para que no ano seguinte, fosse montada uma operação na região, para a qual se contratou o E. A. A. F. - Equipo Argentino de Antropologia Forense. Na ocasião foram localizados os restos mortais de duas pessoas: a de Maria Lucia Petit, identificada em 1996, e a ossada de Bergson Gurjão Farias, identificada apenas em 2009(JUSTAMAND, Michel; MECHI, Patrícia Sposito \& FUNARI, Pedro Paulo A. 2014).

Em 2001, a partir das necessidades apontadas pelas ações anteriores, novas investigações foram feitas na área da guerrilha do Araguaia e outros locais foram escavados num trabalho realizado pelos arqueólogos do Museu Emílio Goeldi. Entretanto, nessa ocasião não se encontraram evidências nos locais escavados de ter havido sepultamento. As mudanças na paisagem depois de quarenta anos do início da guerrilha e a necessidade de maiores recursos tecnológicos dificultaram os trabalhos, apesar de terem sido levantadas informações sobre nove militantes sepultados e/ou vistos pela última vez na base militar de Bacaba ${ }^{3}$ (JIMÉNEZ, José Vargas 2007), outros seis vistos e/ou enterrados em Xambioá, e quatro militantes em outros locais(MINISTÉRIO PÚBLICO FEDERAL, Procuradoria da República do Pará. Pará 2001).

Novo fôlego para as investigações dos desaparecidos na guerrilha do Araguaia foi dado em 2010, graças à condenação do Estado Brasileiro na Corte Interamericana de Direitos Humanos, órgão da Organização dos Estados Americanos. O motivo foi por não ter punido os responsáveis pela morte e desaparecimento de 62 pessoas. A sentença determina que o Estado brasileiro revele o paradeiro das vítimas, identifique-as e entregue seus restos mortais aos familiares, além de prestar atendimento médico, psicológico e psiquiátrico, quando necessário(MECHI, Patricia Sposito 2013).

A partir dessa condenação, foi criado o Grupo de Trabalho Araguaia, GTA, coordenado conjuntamente pela Secretaria de Direitos Humanos da Presidência da República (SDH/PR) e pelos Ministérios da Justiça e Defesa. O grupo conta com o apoio de equipe técnica pericial e as expedições são acompanhadas por familiares dos mortos ou desaparecidos da guerrilha e

\footnotetext{
${ }^{3}$ Bacaba era uma das bases que as Forças Armadas instalaram na região. Funcionando na fazenda de mesmo nome lá foram mantidos presos e torturados cerca de 300 moradores da região. o TenenteCoronel José Vargas Gimenez, que admitiu ter torturado prisioneiros, relata que: "As técnicas de interrogatório a que eram submetidos os guerrilheiros em Bacaba consistiam em choques com corrente elétrica gerada por baterias de telefones de campanha portáteis; telefone, que consistia em dar tapas com força, simultaneamente, nos ouvidos, com as mãos abertas; colocá-los em pé, descalços,em cima de duas latas de leite condensado, apoiando-se somente com um dedo na parede; dar-lhes socos em pontos vitais como fígado, rins, estômago, pescoço, rosto e cabeça; além de fazê-los passar fome e sede". Ver: JIMÉNEZ, José Vargas. 2007. Bacaba - Memórias de um guerreiro de selva da guerrilha do Araguaia. Campo Grande, Editora do Autor.
} 
representantes do Ministério Público Federal (MPF). Ao todo, já foram realizadas cinco expedições na região, muitas delas no cemitério de Xambioá(JUSTAMAND, Michel; MECHI, Patrícia Sposito \& FUNARI, Pedro Paulo A. 2014).

O trabalho ainda inconcluso do GTA já resgatou 25 ossadas que aguardam identificação em Brasília. O foco dos trabalhos, claro, é a identificação das ossadas dos desaparecidos políticos, trabalho que pode ser continuado por algum especialista e/ou sua equipe, sendo de muita valia para os próximos passos da reconstrução da história ainda emudecida da região.

Entre os muitos vestígios passiveis de serem analisados estão: as garrafas, os medicamentos, os projéteis, as pilhas, os recipientes vazios de comida, avaliados pelo GTA, indicativos da existência de uma base de comunicação militar no local (GRUPO DE TRABALHO ARAGUAIA 2011). Vestígios esses que aguardam novos interessados no desenvolvimento da pesquisa arqueológica e forense do Araguaia.

\section{Considerações finais e conclusão}

Consideramos que parte importante da história da ditadura civil-militar brasileira ainda está encoberta. Estaria encoberta por um véu que esconde as ações de agentes de estado que cometeram crimes lesa-humanidade, negando às famílias dos desaparecidos o direito de sepultar os restos mortais de seus entes queridos, e negando à sociedade brasileira a compreensão, em toda a sua plenitude, deste período triste de nosso passado.

Este quadro tem sido vivamente combatido por entidades ligadas aos direitos humanos. Entidades que lutam, entre outras coisas, pela revisão ou revogação da Lei de Anistia de 1979. Visto que se trata de uma lei de autoanistia que protege, na verdade, a muitos dos criminosos e que não está em consonância com os tratados internacionais dos quais o Brasil é signatário.

As famílias dos desaparecidos ainda aguardam os corpos para os justos e devidos enterros. Esperam também esclarecimentos, indenizações do estado, por ocultação de cadáveres, sequestro, desaparecimentos, assassinatos, etc. Essas mesmas famílias lembram que os criminosos não podem continuar impunes. Além dos militantes mortos, há mães desses desaparecidos, que também foram mortas, por reivindicarem a volta dos seus filhos ou a entrega dos corpos. Esses são vestígios de um estado terrorista. 
O estado brasileiro foi condenado na corte internacional das Américas a dar conta dos corpos dos desaparecidos e acertar definitivamente as contas com a sua História e com aqueles que perderam a vida, mas deixaram um legado histórico de luta.

Ainda a passos lentos, o estado e a sociedade do Brasil avançam, a exemplo de sindicâncias promovidas pelas próprias instituições militares, aeronáutica, marinha e exército. Segundo o coordenador da CNV (Comissão Nacional da Verdade), Pedro Dallari, essa iniciativa é um fato inédito na história das Forças Armadas, que nunca haviam se predisposto a fazer esta investigação. É um gesto de reconhecimento de que graves violações de direitos foram uma realidade nesses estabelecimentos. Segundo Dallari, as Forças Armadas entenderam que precisam contribuir com a sociedade no esclarecimento do que ocorreu(UOL 2014).

Os arqueólogos em ação na região da guerrilha, com os vestígios em mãos, podem contribuir para os esclarecimentos, a partir das técnicas e interpretações, cooperando para a construção da memória social. Desta forma, a ciência arqueológica é colaborativa com as praticas dos direitos humanos. Exumar eventos dolorosos também é um fazer arqueológico, haja vista toda a produção científica já realizada nessa área, especialmente na América Latina(FUNARI, Pedro Paulo; ZARANKIN, Andrés \& REIS, José Alberioni dos 2008).

\section{Referencias bibliográficas}

ABREU, S. de B. De Zé Porfírio ao MST: A luta pela terra em Goiás. 2002. Brasília, André Quicé Editor.

CARVALHO, Aline Vieira de e FUNARI, Pedro Paulo A. 2009. A importância da Arqueologia Forense na construção das memórias perdidas nos períodos ditatoriais latino-americano. In: SOARES, Inês Virgínia Prado e KISHI, Sandra Akemi Shimada (coord.). Memória e verdade: a justiça de transição no estado democrático brasileiro. Belo Horizonte: Fórum.

CARVALHO, Aline Vieira de e FUNARI, Pedro Paulo A. 2009. Arqueologia forense como arqueologia pública: estado da arte e perspectivas para o futuro no Brasil. In: CARVALHO, Aline Vieira de; SOARES, Inês Virgínia Prado; FUNARI, Pedro Paulo A. \& SILVA, Sérgio Francisco Serafim Monteiro. Arqueologia, direito e democracia. Erechim: Habilis.

COMISSÃO DE FAMILIARES DE MORTOS E DESAPARECIDOS POLÍTICOS; INSTITUTO DE ESTUDOS DA VIOLÊNCIA DO ESTADO; GRUPO TORTURA NUNCA MAIS. 1996. Dossiê dos mortos e desaparecidos políticos a partir de 1964. São Paulo, Imprensa Oficial do Estado. 
DIAS Filho, Claudemir Rodrigues. 2009. Entomologia forense e remanescentes humanos. In: CARVALHO, Aline Vieira de; SOARES, Inês Virgínia Prado; FUNARI, Pedro Paulo A. \& SILVA, Sérgio Francisco Serafim Monteiro. Arqueologia, direito e democracia. Erechim: Habilis.

FUNARI, Pedro Paulo de Abreu. 2010. Arqueologia. São Paulo: Contexto.

FUNARI, Pedro P. A. 2013. "Arqueologia no Brasil e no mundo: origens, problemáticas e tendências". Ciência e Cultura [online]. Vol.65, n.2.

FUNARI, Pedro Paulo A. e SOARES, Inês Virginia Prado. No prelo. Arqueologia da resistência e dos direitos humanos.

FUNARI, Pedro Paulo; ZARANKIN, Andrés \& REIS, José Alberioni dos. 2008. Arqueologia da repressão e da resistência: América Latina na era das ditaduras (décadas de 1960-1980). São Paulo: AnnaBlume e FAPESP.

GRUPO DE TRABALHO ARAGUAIA. Relatório de conclusão. 04 de novembro de 2011, fl 22. Disponível em: $\quad$ http://2ccr.pgr.mpf.gov.br/coordenacao/grupos-de-trabalho/justica-detransicao/relatorios-1/relatorio-final-gta-2011/Relatorio\%20Final\%20de\%202011.PDFacessado em:10 de julho de 2012.

http://noticias.uol.com.br/politica/ultimas-noticias/2014/04/01/pela-1-vez-forcas-armadas-reconhecemviolacoes-na-ditadura-diz-coordenador-da-cnv.htm

JIMÉNEZ, José Vargas. 2007. Bacaba - Memórias de um guerreiro de selva da guerrilha do Araguaia. Campo Grande, Editora do Autor.

JUSTAMAND, Michel; MECHI, Patrícia Sposito \& FUNARI, Pedro Paulo A. 2014. Repressão política e direitos humanos: arqueologia, história e memória da ditadura militar brasileira, in: $\mathrm{MECHI}$, Patricia Sposito \& MELO, Wanderson Fábio. Questões da ditadura: vigilância, repressão, projetos e contestações. Palmas: Editora da UFT.

KEELEY, Lawrence H. 2011. A guerra antes de civilização. Trad. Fábio Faria. São Paulo: É Realizações.

MECHI, Patrícia Sposito. 2012. Protagonistas do Araguaia: trajetória, representações e práticas de camponeses, militantes e militares na guerrilha. Tese de Doutorado, PUC-SP.

MECHI, Patricia Sposito. Março de 2013. "Contra a revolução, a barbárie”.Revista de História da Biblioteca Nacional. Dossiê Guerrilhas. n. 90.

MINISTÉRIO PÚBLICO FEDERAL, Procuradoria da República do Pará. Pará, junho de 2001. Inquérito Civil Público. Assunto: Direitos Humanos. Guerrilha do Araguaia. Investigação visando localizar os restos mortais de vítimas da repressão política.

MINISTÉRIO PÚBLICO FEDERAL, Procuradorias da República do Pará, São Paulo e Distrito Federal. Brasília, janeiro de 2002. Relatório Parcial das Investigações sobre a guerrilha do Araguaia.

(C) Rev. Arqueologia Pública \begin{tabular}{l|l} 
Campinas, SP & v.9
\end{tabular} No.(11) p.122-133 suplemento ISSN 2237-8294 
MORAIS, Taís e SILVA, Eumano. 2005. Operação Araguaia: os arquivos secretos da Guerrilha do Araguaia. São Paulo, Geração Editorial.

NASCIMENTO, Durbens Martins. 2000. Guerrilha do Araguaia: Paulistas e militares na Amazônia. (Dissertação de Mestrado). Universidade Federal do Pará.

S. NAVARRETE, Rodrigo e Y. LÓPEZ, Ana Maria. Rabiscando atrás das grades: grafites e imaginário político-simbólico no Quartel San Caelos (Caracas/Venezuela). 2008. In: FUNARI, Pedro Paulo; ZARANKIN, Andrés \& REIS, José Alberioni dos. Arqueologia da repressão e da resistência: América Latina na era das ditaduras (décadas de 1960-1980). São Paulo: AnnaBlume e FAPESP.

SOARES, Inês Virgínia Prado \& KISHI, Sandra Akemi Shimada. 2009. Memória e verdade: a justiça de transição no estado democrático brasileiro. Belo Horizonte: Fórum.

ZARANKIN, Andrés e FUNARI, Pedro Paulo A. 2009. "Brilho eterno de uma mente sem lembranças": arqueologia e construção da memória da repressão militar na América do Sul (1960-1980). In: CARVALHO, Aline Vieira de; SOARES, Inês Virgínia Prado; FUNARI, Pedro Paulo A. \& SILVA, Sérgio Francisco Serafim Monteiro. Arqueologia, direito e democracia. Erechim: Habilis.

ZARANKIN, Andrés e NIRO, Claudio. 2008. A materialização do sadismo: arqueologia da arquitetura dos Centos Clandestinos de Detenção da Ditadura militar argentina (1976-1983). In: FUNARI, Pedro Paulo; ZARANKIN, Andrés \& REIS, José Alberioni dos. Arqueologia da repressão e da resistência: América Latina na era das ditaduras (décadas de 1960-1980). São Paulo: AnnaBlume e FAPESP. 